\title{
Erratum to: The Reciprocal Relationship Between Gang Involvement and Victimization by Peers: Findings from the Pittsburgh Girls Study
}

\author{
Amanda B. Gilman ${ }^{1}$ • James C. Howell ${ }^{2}$. \\ Alison E. Hipwell ${ }^{3} \cdot$ Stephanie D. Stepp $^{3}$
}

Published online: 12 November 2016

C) Springer International Publishing AG 2016

\section{Erratum to: J Dev Life Course Criminology DOI 10.1007/s40865-016-0046-1}

The original version of this article unfortunately contained mistakes and the authors hereby publishing these corrections.

The sentence on page 13 in the published paper is misleading: "Thus, the approach taken to prevent gang involvement as well as intervene with actively involved girls needs to move away from the purely punitive strategies seen in many systems that girls are engaged in, such as zero tolerance policies in schools and gang enhancement laws in juvenile justice systems." Instead, it should read: "Thus, the approach taken to prevent gang involvement as well as intervene with actively involved girls needs to move away from the purely punitive strategies seen in many systems that girls are engaged in, such as zero tolerance policies in schools and criminal gang enhancement laws that are imposed on juvenile offenders."

With these, the original article was corrected.

The online version of the original article can be found at http://dx.doi.org/10.1007/s40865-016-0046-1.

Amanda B. Gilman

amanda.gilman@courts.wa.gov

1 Washington State Center for Court Research, Administrative Office of the Courts, 1206 Quince St. SE, Olympia, WA 98504, USA

2 National Gang Center, Institute for Intergovernmental Research, P.O. Box 12729, Tallahassee, FL 32317, USA

3 Department of Psychiatry, University of Pittsburgh School of Medicine, 3811 O'Hara St, Pittsburgh, PA 15213, USA 